only in this position and even slept in this manner. This was not an individual habit and had not been present before the onset of this illness. The only other physical signs were in the abdomen, where there was slight general distension and a characteristic tumour palpable in the left iliac fossa. Rectal examination was normal.

Laparotomy was performed that evening, and an easily reducible caecocolic intussusception was found, which, owing to partial spontaneous reduction, was in the left hypochondrium. Numerous enlarged lymph nodes were found in the mesentery, and histological examination of one of these showed reactive hyperplasia. The child made an uneventful recovery.

The position adopted by this child clearly relieved his pain, and in view of the anatomy in this particular case it would seem likely that the child was unconsciously using gravity in an attempt to reduce the intussusception. This sign does not feature in textbooks and is obviously unusual. It was not encountered in any of 67 cases described in clinical detail by Kark and Rundle. ${ }^{1}$ However, although unusual, the sign is a dramatic one and should alert one to the diagnosis at a glance if its significance is appreciated.

J F B DOSSETOR

Department of Paediatrics

Ahmadu Bello University Hospital
Zaria, Nigeria

1 Kark, A E, and Rundle, W J, British fournal of Surgery, 1960, 48, 296.

\section{Fear of ECT}

Sir,-What is "inexplicable" (28 August, p 526) to me is that no responsible medical body appears to have made any attempt to allay the fear engendered among filmgoers by the demonstration of punitive, unmodified ECT in "One Flew over the Cuckoo's Nest."

London W1

L Rose

"Market research"

SIR,-I have recently received from a market research company a request to fill in a questionnaire about each drug company representative visiting me in the month of September, the drugs which they offer, and those which 1 prescribe. The paltry bribe offered for doing this very detailed work is a book or record to be chosen from a given list.

An obvious purpose which this might have is to get me to gather information about drug companies' sales methods, presumably for somè client among the various drug companies. This in other fields is a known form of industrial espionage. I consider this approach impudent and the method distasteful, and I am sure that many GPs will agree with me.

Sheila J HANDEL

London W3

\section{Lymphoma in dermatitis herpetiformis}

SIR,-We would like to report a case of dermatitis herpetiformis associated with the development of lymphocytic lymphoma of the skin. Although the association between adult coeliac disease and lymphomas developing outside the gastrointestinal tract is well recognised, ${ }^{1}$ this appears to be only the second 42, 899. P, and Fry, L, Proceedings of the Royal
2 Goodwin, P, and Fry
Society of Medicine, 1973, 66, 625.
' Berrill, W T, et al, Lancet, $1975,2,1006$.
' Robinson, T J, British Medical fournal, 1976, $1,745$.

confirmed case of dermatitis herpetiformis with villous atrophy in which lymphoma subsequently developed. ${ }^{2}$

The patient, a man aged 59, presented after three months' progressive dyspnoea. His chest $x$-ray appeared to show fibrosing alveolitis with fibrosis around a cavity in the right apex. Because of the association between fibrosing alveolitis and gluten enteropathy ${ }^{3}$ 4 the following investigations were performed: rheumatoid screen, positive; sheep cell agglutination test and reticulin antibody, negative. Tests for avian precipitins, and those for Aspergillus fumigatus and Micropolyspora faeni were also negative. Pulmonary tuberculosis was excluded by a weekly positive tine test and negative sputum cultures.

He had had treated dermatitis herpetiformis for seven years, and jejunal biopsy showed subtotal villous atrophy. Steroids were given for the severe breathlessness and produced a short-lived dramatic improvement without change in serial chest $x$-rays. $\mathrm{He}$ was also started on a gluten-free diet. $\mathrm{He}$ remained ill, and although lung biopsy was considered, this remained impracticable owing to his breathlessness. Shortly before his death he developed widespread papillomatous skin lesions which on biopsy proved to be lymphocytic lympoma. He died from septicaemia and no necropsy was held.

This is the second case report of a lymphoma developing in dermatitis herpetiformis, giving added weight to the hypothesis that adult coeliac disease and dermatitis herpetiformis are prone to the same complications. We also feel that the appearance of fibrosing alveolitis and the cavity in the chest $x$-ray might represent a cavitating lymphomatous tumour. This is speculative as unfortunately permission for a post-mortem examination was refused.

J M FOWLER

D J B THOMAS

Basingstoke District Hospital,

Basingstoke, Hants

\section{Misleading chest x-ray film in psoriasis}

SIR,-A 30-year-old man was recently admitted here for treatment of long-standing psoriasis. During his stay we had reason to take chest $x$-rays, which were reported as showing multiple calcific foci in soft tissues and overlying the lung fields. These were consistent with cysticercosis. Further views were taken of the thighs and buttocks, but these were normal.

Closer investigation showed that the initial

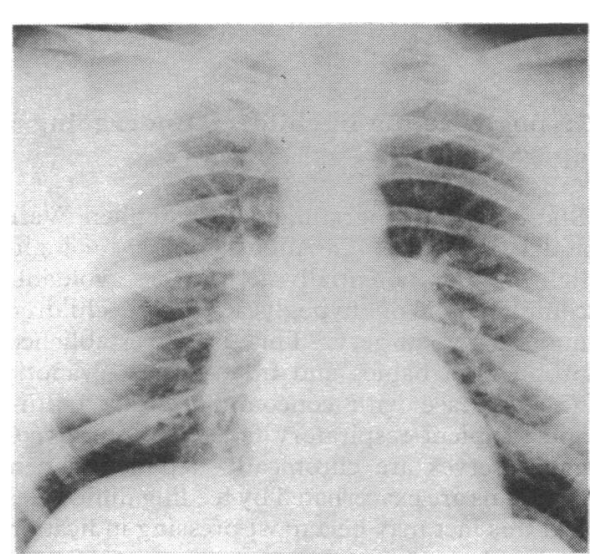

1 Harris, O D, et al, American fournal of Medicine, 1967, films had been taken after application of a standard preparation of dithranol in Lassar's paste (zinc oxide $24 \%$, salicylic acid $2 \%$ starch and white soft paraffin to $100 \%$ ) to the psoriatic plaques on the chest. However, these areas did not match the $x$-ray appearances, being far greater in size and distribution. There were no palpable subcutaneous nodules.

It was later realised that Tubegauze had been applied as a protective "vest" after treatment and this was later seen to cause the formation of balls of Lassar's paste by frictiona movement. The latter were the opacities seen on $x$-ray, a repeat film minus Lassar's paste being normal. The doctor's lesson is always to $x$-ray patients with skin disease before the application of topical medicaments, an oversight in this case leading to unnecessary worry and extra investigations.

\section{G A R Price}

Department of Dermatology, Liverpool Royal Infirmary,

\section{School pregnancies}

SIR,-In your leading article on this subject (4 September, p 545) you state that a girl under the age of 16 years cannot marry. This is not so. The Registrar General's annual statistics record the number of marriages of women under 16 years of age and the numbers of such are often over 1000 . The reason is that in Northern Ireland the legal age of marriage is 15 years, and every year many girls who are over 15 and under 16 and who become pregnant go to Northern Ireland for three weeks and are then able legally to marry.

It is a strange thing that very few people in Great Britain are aware of this-except parish priests. I have asked bishops, barristers, MPs, a judge, and even registrars if a girl under the age of 16 years can marry and the answer is always, "certainly not."

Leafield, Oxford

D W G BARTLETT

\section{Home treatment of convulsions}

SIR,-Even today some patients are left in convulsions for some considerable time before being given effective treatment.

May I suggest that suitable prepacked syringes of, say, diazepam be made available to the parents or relatives of patients at risk ? With careful instructions and graded dosages to suit all ages the risks of such a scheme would seem to be minimal.

A STEPHEN

Bingley,
Yorks

\section{Iodine content of food}

SIR,-We recently expressed our concern over the indiscriminate contamination of common foods with iodine and the possible harmful consequences (14 February, $p$ 372). It is illustrative of the complexity of dietary management that we now find ourselves concerned that over-reaction to the dangers of excess iodine may lead to ill-considered intervention. We are led to believe, for example, that in some states of Australia a complete ban on the use of iodophors in the dairy industry has been considered. 
The virtual elimination of juvenile goitre which has been witnessed in Tasmania over the past decade $^{1}$ has been attributed to the deliberate addition of iodate to bread improver and thus to all commercially baked bread. Subsequently it has become apparent that the increased iodine content of milk derived from the use of iodophors in the dairy industry also contributed to improved iodine nutrition. Recent surveys conducted by the Department of Public Health show that: (1) bread consumption by schoolchildren is falling, (2) a proliferation in available bread improvers makes it impossible to guarantee the iodine content of bread, and (3) a substantial proportion of schoolchildren are now dependent on the iodine they derive from milk to maintain iodine sufficiency. Should iodophors be withdrawn and the iodine content of milk revert to low levels many children would again be iodine-deficient.

No doubt in other areas of iodine deficiency the contamination of milk with iodine from iodophor residues has led to relief of the deficiency and the price has already been paid in an increase of thyrotoxicosis in the middleaged and elderly. To ban iodophors in these circumstances would rob the young of the benefits for which their elders have already paid. A detailed study by Dunsmore and Wheeler $^{2}$ has shown that with correct usage iodophors need add no more than $1.2 \mu \mathrm{mol} / \mathrm{l}$ $(15 \mu \mathrm{g} / 100 \mathrm{ml})$ to the iodine content of milk. Iodine at this level is not excessive and milk is a suitable vehicle for goitre prophylaxis as its consumption tends to be higher in the young than the old.

Our plea is that iodine contamination of food should be controlled but not necessarily banned and that action should be taken only after a full appraisal of the local circumstances in relation to goitre incidence and iodine nutrition.

J C STEWART G I VIDOR

Thyroid Clinic,

Launceston General Hospital,

Launceston, Tasmania

' Tasmanian Thyroid Advisory Committee, unpublished

data.
Dunsmore, D S, and Wheeler, A M, Australian fournal of Dairy Technology. In press.

\section{Chronic urticaria}

SIR,-As a comment on your leading article on this subject ( 10 July, p 68) we should like to report results obtained in our urticaria clinic set up nine months ago.

Of 72 patients, 37 had chronic urticaria (that is, urticaria occurring for two months or longer) and were in an active phase at the time of attendance. Most had been treated with two or more antihistamines unsuccessfully before referral. All were routinely investigated, as a result of which three patients were found to have antistreptolysin 0 titres of $>300$ units $\mathrm{ml}$ and $\beta$-haemolytic streptococci were grown from throat swabs from two further patients. Two patients were found to be thyrotoxic and one man, who had had a previous nephrectomy, had a urinary infection. Three patients had signs of old and persistent sinus infection.

Each patient also had an intradermal Candida albicans prick test (Bencard) and was given a series of identical capsules containing tartrazine, sodium benzoate, 4-hydroxybenzoic acid, yeast extract, penicillin, and aspirin
$100 \mathrm{mg}$ and $600 \mathrm{mg}$ interspersed with control capsules as described by Warin and Smith. ${ }^{1}$ This was done at a time when the urticaria was partially but not totally controlled by an oral antihistamine. Only one patient had a weakly positive type I response to the $C$ albicans skin test and only two patients had reproducibly positive reactions to the oral provocation capsules. A third patient had a strongly positive reaction after the administration of aspirin $100 \mathrm{mg}$ and it was felt unsafe to repeat the test. A fourth patient reacted strongly to tartrazine administration; owing to the activity of his urticaria rechallenging was not possible, but a low-tartrazine diet produced an excellent response. Of the two patients with reproducible reactions, one, who reacted to sodium benzoate administration, cleared completely on a lowbenzoate diet. The other reacted to penicillin and her urticaria cleared on a diet low in milk products. All patients were advised to avoid aspirin. ${ }^{2}$

The administration of the rather large capsules has not proved a problem. We advise that they be taken with a hot drink on waking Nearly all the patients developed urticaria after administration of the first capsule (a control) and many of them had weals throughout the test period.

Although it is too early to draw definite conclusions from this study we have not been able to confirm previous work using test capsules which showed positive reactions in 66 out of 111 patients. ${ }^{1}$ In particular, with the dosages of aspirin employed we have seen an exacerbation of urticaria on only one occasion and this is a man already known to be aspirin-sensitive. As yet we cannot know whether the improvement in the three patients treated by diet is due to the diets alone. If it is, does it justify the lengthy screening procedure involved or is there an easier way to locate the offending substance?

The lack of reactions to $C$ albicans intradermal prick testing is also at variance with James and Warin's work." They reported that $11^{\circ}$ of patients with chronic urticaria had positive prick tests (type I response) with $C$ albicans out of a total of $36^{\circ}$ o positive reactors.

We are surprised at our very differen findings from the previous series and would be interested to hear of other workers' experience.

A E SOLOMON J MaCAULAY

Departments of Dermatology and Pharmacy, Gow Infirmary, Glasgow

' Warin, R P, and Smith, R J, British fournal of Dermatology, 1976, 94, 401.
Moore-Robinson, M, and Warin, R P, British Medical fournal, $1967,4,62$ James, J, and Warin, R P, British fournal of Der-
matology, 1971, 83, 227.

\section{Hypoglycaemia in children undergoing} operations

SIR,-May I congratulate Drs Stephen Ware and J P Osborne (28 August, p 499) for highlighting the potentially lethal but avoidable complication of hypoglycaemia in children undergoing surgery. This is an established problem in babies and infants with cyanotic heart disease with concomitant heart failure and incipient respiratory failure whose glycogen reserves are chronically depleted. Their problems are exacerbated by feeding difficulties and this fact may be a most pressing indication for palliative surgery-for example, a Blalock shunt.

A method for preventing hypoglycaemia in these small patients has been used in this hospital for the past two years. The infant receives his last feed either by mouth or via a nasogastric tube three hours before the estimated time for induction of anaesthesia. During surgery the child receives intravenous fluids as Hartmann's solution $5-7 \mathrm{ml} / \mathrm{kg}$ body weight per hour, plus $0.2 \mathrm{~g}$ glucose $\mathrm{kg}$ body weight per hour as a $50^{\circ} \%$ solution by continuous infusion. This regimen is continued in the postoperative period, $50 \%$ glucose solution being given as a quarter of the infant's calculated total hourly fluid requirement, again by continuous infusion. Both during and after surgery the hypertonic fluid is administered through a centrally placed venous catheter inserted percutaneously via the right internal jugular vein.

Blood glucose estimations are performed two-hourly until oral or nasogastric feeding with milk has been re-established and further $50 \%$ glucose is administered if the blood glucose level is below $8 \mathrm{mmol} / \mathrm{l}(144 \mathrm{mg} / 100$ $\mathrm{ml}$ ).

Since the institution of this regimen there has been no mortality or obvious morbidity in this group of patients attributable to hypoglycaemia.

\section{Department of Anaesthetics,}

National Heart Hospital,

London W1

\section{BMA and HCSA}

SIR,-We are sure we are only a few of the many inside and outside the medical profession who never cease to be amazed at the ease with which divisions of opinion are generated and sustained among medical personnel in the hospital service, between seniors and juniors, between whole-timers and parttimers, between BMA and Hospital Consultants and Specialists Association, and so on ad nauseam.

We would have hoped, in vain it seems, that it would by now have become apparent to the profession that the possibility of resolving any given conflict of interests to the satisfaction of all of us is a myth. We would further have hoped that it would by now have come to be recognised that the exercise of consultation with all concerned on every occasion and at every turn, while basically commendable, has become a disease of the era which, carried to the extreme, becomes a lunatic performance which terminally will ensure that no satisfactory conclusion or outcome can possibly be reached.

Surely we have now arrived at the point where the consultative process must be followed by a straightforward, uncomplicated unqualified support of our negotiators, briefed to pursue the policies acceptable to the majority so that they may proceed secure in the knowledge that we will do all they require of us to ensure that the Government will not be able to retain the entrenched position it has in relation to consultant medical staff up to the present time.

Finally, please let us say to the BMA and the HCSA, the bickering must cease. We expect you to speak with one voice to secure conditions of service and remuneration which will restore morale among us, without which restoration there can be little hope of the 